\title{
Patterns of malaria related mortality based on verbal autopsy in Muleba District, north-western Tanzania
}

\author{
G.M. KAATANO ${ }^{1}$, F.M. MASHAURI ${ }^{1}$, S.M. KINUNG ${ }^{\prime} I^{1}{ }^{1}$, J.R. MWANGA ${ }^{1}$, R.C. MALIMA ${ }^{2}$, C. \\ KISHAMAWE ${ }^{1}$, S.E. NNKO ${ }^{1}$, S.M. MAGESA ${ }^{2}$ and L.E.G. MBOERA ${ }^{3}$ \\ ${ }^{1}$ National Institute for Medical Research, Mwanza Research Centre, P.O. Box 1462, Mwanza, Tanzania \\ ${ }^{2}$ National Institute for Medical Research, Amani Research Centre, P.O. Box 81 Muheza, Tanzania \\ ${ }^{3}$ National Institute for Medical Research, Headquarters, P.O Box 9653, Dar es Salaam, Tanzania
}

\begin{abstract}
Reliable malaria related mortality data is important for planning appropriate interventions. However, there is scarce information on the pattern of malaria related mortality in epidemic prone districts of Tanzania. This study was carried out to determine malaria related mortality and establish its trend change over time in both epidemic and non-epidemic areas of Muleba District of north-western Tanzania. A verbal autopsy survey was conducted to obtain data on all deaths of individuals who died in six randomly selected villages from 1997 to 2006 . Relatives of the deceased were interviewed using a standardized questionnaire. Communicable diseases accounted for about two thirds $(61.9 \%)$ of deaths among $\geq 5$ years individuals and $84.8 \%$ in $\leq 5$ years. Non-communicable diseases accounted for $28.9 \%$ and $14.1 \%$ deaths in $\geq 5$ years and $\leq 5$ years, respectively. Malaria was the leading cause of deaths in all age groups $(40.3 \%)$ and among children $<5$ years $(73.8 \%)$. Infants accounted for about two third $(64.5 \%)$ of all malaria related deaths in children $<5$ years. Peak of malaria proportional mortality was highest during malaria epidemics. Most of the malaria-related deaths in this group were among 1-12 months (64.5\%) followed by 13-24 months (20.9\%), and 2559 months $(14.8 \%)$. Cerebral malaria accounted for $18.9 \%(\mathrm{~N}=32)$ of death related to malaria in all age groups; $12.1 \%$ (17/141) were in under-five, $42.9 \%$ (6/14) were in 5-14 years and 64.3\% (9/14) in 15-70 years old. More than half of malaria related deaths $(61.0 \%)$ in $<5$ years children were associated with severe anaemia followed by diarrhoeal disease $(24.1 \%)$, cerebral malaria $(12.5 \%)$ and respiratory infection (8.5\%) as common conditions. The majority of the deceased caretakers first sought treatment at health facilities within $24 \mathrm{hr}$ of the onset of illness. Significantly a higher proportion of caretakers of the underfives in the epidemic area sought treatment within $24 \mathrm{hr}$ than in non-epidemic area $(39.3 \%$ vs. $18.5 \%$; $P=0.0385)$. In conclusion, malaria accounts for majority of deaths in Muleba district, with substantial proportion being attributed to malaria epidemics.
\end{abstract}

Key words: malaria, epidemics, mortality, verbal autopsy, Tanzania

\section{Introduction}

Malaria is the most important parasitic disease in Tanzania, causing high morbidity and mortality, particularly among pregnant women and young children. It accounts for more than one-third of deaths of under-five children and to one-fifth of deaths among pregnant women $(\mathrm{MoH}, 2006)$. Statistics indicate that over $95 \%$ of about 40 million people in Tanzania are at risk for malaria infection. In recent years malaria in Tanzania have extended into previously nonendemic or low transmission areas (Mboera \& Kitua, 2001; Maegga et al., 2005). Twenty-five percent of the districts are malaria epidemic prone (Mboera et al., 2007).

A number of challenges have been identified to face malaria control in Tanzania.
They include inadequate human and financial resources, inefficiency healthcare system, and lack of an efficient disease surveillance system (Mboera et al., 2007). Although Tanzania adopted the WHO Integrated Disease Surveillance and Response strategy in 1998, its health management information system (HMIS) is still underdeveloped (Mghamba et al., 2004; Rumisha et al., 2007). Most of epidemiological information is health facility-based data; which is incomplete, untimely and unreliable. Despite these limitations with HMIS, in most cases the health facility-based data underestimates the actual magnitude of mortality due to the fact that many deaths in developing countries, including Tanzania, occur outside health setting (Lopez, 1990). The lack of reliable data on the magnitude and cause(s) of death in developing

\footnotetext{
* Correspondence: Dr. Godfrey M. Kaatano; E-mail: gmkaatano@yahoo.com
} 
countries has implication on the capacity for planning, monitoring and evaluation of health interventions.

In recent years, verbal autopsy has been adopted as a partial solution to the health information problem and has become the primary source of information about causes of deaths among populations that lack vital registration and medical certification (Soleman et al., 2006). Despite its low sensitivity and specificity, verbal autopsy, has been used to determine malariaspecific cause of death for community-based studies in many endemic areas (Snow et al., 1992; Salum et al., 1994; Premji et al., 1997; Kamugisha et al., 2007). However, such studies in Tanzania have mostly focused on childhood malaria in area of intense transmission (Salum et al.,1994; Premji et al., 1997) and only few have included malaria low transmission areas (Kamugisha et al., 2007). In areas of unstable and low malaria transmission, all age groups of the population are at increased risk of severe malaria and death (Snow et al., 1997; Marsh \& Snow 1999) than in endemic areas.

Malaria epidemics have been increasingly reported in various part of Tanzania due to various factors (Garay, 1998; Mboera \& Kitua, 2001; Mboera, 2004). Muleba district is among districts in Tanzania, highly affected by malaria epidemics in recent years. The first most devastating malaria epidemic occurred in 1997/98 following the EL- Nino rains. Delayed treatment seeking, antimalarial drug resistance, disruption of the infrastructure and poor health delivery system were the most likely factors that contributed to the high mortality rates observed in Muleba District (Garay, 1998). The district experienced another malaria epidemic in recent years (2006). The government responded to the epidemic by changing the first line antimalarial drug from sulfadoxine-pyrimethamine to artemether-lumefantrine in Muleba district. This was followed by introduction of indoor residual spraying in 2007.

In this study, a verbal autopsy survey was done to assess the magnitude of malaria related mortality, compare pattern of malaria mortality among children and adult between epidemic and non-epidemic areas and establish their trend change over a period 10 years (1997-2006) in Muleba District, north-western Tanzania

\section{Materials and Methods}

\section{Study area and population}

Muleba District $\left(1^{0}, 45^{\prime} \mathrm{N}, 31^{0}, 40^{\prime} \mathrm{E}\right)$ is in northwest of Tanzania and most part of the district lie at $1200-1500 \mathrm{~m}$. Administratively the district has 5 divisions, 31 wards, and 134 villages. It has a population of 425,172 people (URT, 2002) with $85,035(20 \%)$ being children $<5$ years. The district has 3 hospitals (Rubya, Kagondo and Ndolage), 4 health centres and 29 dispensaries. Most of its inhabitants are subsistence farmers of coffee and banana. Malaria is the leading cause of death in Muleba district, contributing to $64.2 \%$ of deaths in under-five children and $34.6 \%$ in $\geq 5$ years (Kagera Region Report, 2005 unpubl.). A recent study has indicated an overall prevalence of malarial infection of $49-53.3 \%$ in Muleba district (Mboera et al., 2006).

The study was conducted in six randomly selected villages which were stratified into two groups; villages that experienced the 2006 malaria epidemics (epidemic areas), and villages which were not affected (nonepidemic areas). Villages in the epidemic area were Ijumbi and Nshambya (in Ijumbi ward) located in the relatively high altitude area and Ikondo village (in Ikondo ward) located in the lowland area. Villages in the non-epidemic area were Bushemba (in Buganguzi ward) and Bunywambele (in Ibuga ward) of which all were located in the highlands and Kibanga (in Kibanga ward) which was located in the lowlands. In each village two sub-villages were randomly selected from a list of sub-villages. For each village in the non-epidemic area, one more subvillage was included in the study to facilitate comparability of two arms (epidemic and nonepidemic areas) after it has been observed that non-epidemic villages had relatively lower death rates compared to villages in the epidemic area. Overall, 15 sub-villages were included in the study; 6 from epidemic area and 9 from the non-epidemic area. From each selected subvillage, all households with a history of death within a period of 10 years from 1997 to 2006 were identified, and listed in a checklist. The checklist had the date of census, name of the deceased, sex, age at time of death, date of death and name of the head of household.

\section{Verbal autopsy procedure}

TheWorldHealthOrganization's standard verbal autopsy (VA) questionnaires (WHO, 2007) with slight modification to suit the local setting, was employed. The questionnaires were translated into Kiswahili and pre-tested before being used in the field survey. The questionnaire assessed the identity of the deceased and established the 
sequence of events leading to death including symptoms and signs of the illness.

Two trained physicians with local experience independently reviewed verbal autopsy questionnaire to determine the most likely causes of death. Multiple underlying causes of deaths were identified by the two physicians. None of the physicians were aware of the study. The VA forms were coded only with one principal underlying cause of death and other conditions as immediate cause of death. When there were discordances between the physicians about the cause of death, they met and discussed to reach a consensus.

\section{Data analysis}

Data was entered into SPSS version 11 (SPSS, Chicago, IL, USA) statistical software package for analysis. Age was categorized as 1-59 months, 5 -14 years and 15-70 years groups. However, for the under fives, age categories included 1-12 months, 13-24 months and 25 months and above. Malaria proportional mortality and prevalence was determined by generation of frequency tables and cross tabulations. Malaria proportional mortality was applied to establish malaria mortality trend over time and compared pattern by age groups and place of death between epidemic and nonepidemic areas. Pearson's $\mathrm{X}^{2}$ test was used to compare proportion (prevalence) between two arms (epidemic and non-epidemic areas) and categorical data.

\section{Ethical considerations}

The study received ethical approval from the Medical Research Coordinating Committee of the National Institute for Medical Research. Verbal informed consent was sought from each respondent before the questionnaire was administered.

\section{Results}

A total of 508 deaths were listed during the survey, $285(56.1 \%)$ from epidemic villages and $223(43.9 \%)$ from non-epidemic villages (control). Verbal autopsies were successfully carried out for 419 deaths $(82.5 \%)$, of which 51.8 $\%$ were males. Out of the 419 successful VAs, $194(46.3 \%)$ were adults (15-70 years), $45.6 \%$ were under-five children and $8.1 \%$ were aged 5-14 years. Probable cause of death could not be determined for $23(5.5 \%)$ deaths, and the majority (21) were among $\geq 5$ years. Of the reported deaths, $243(58.0 \%)$ occurred at heath facilities and 169 (42\%) occurred outside health facilities. The majority of deaths $(72.1 \%)$ were attributed to communicable diseases which accounted for $62.0 \%$ of deaths among $\geq 5$ years and $84.8 \%$ in under-fives. Malaria was leading cause of death in all age groups accounting for $40.3 \%$ ( $\mathrm{N}=169)$ followed by HIV / AIDS $(19.1 \%)$, cardiovascular diseases $(3.6 \%)$, pneumonia $(3.3 \%)$, protein energy malnutrition $(3.3 \%)$ and sickle cell disease $(2.6 \%)$.

Table1. Distribution of causes of death by sex among individuals $\geq 5$ years old in Muleba $(\mathrm{N}=228)$

\begin{tabular}{llll}
\hline Type of disease condition & Sex & & All \\
& Female N (\%) & Males N (\%) & N (\%) \\
\hline HIV / AIDS & $37(36.3)$ & $40(31.8)$ & $77(33.8)$ \\
Malaria & $17(16.7)$ & $13(13.7)$ & $21(11.4)$ \\
Cardiovascular disease & $6(5.9)$ & $7(5.6)$ & $13(5.7)$ \\
Pneumonia & $5(4.9)$ & $4(3.2)$ & $9(4.0)$ \\
Tuberculosis & $3(2.9)$ & $6(4.8)$ & $9(4.0)$ \\
Sickle Cell Disease & $3(2.9)$ & $5(4.0)$ & $8(3.5)$ \\
Injuries & $1(1.0)$ & $7(5.6)$ & $8(3.5)$ \\
Neurological lesion/diseases & $3(2.9)$ & $4(3.2)$ & $7(3.1)$ \\
Maternal/ reproductive conditions & $7(6.9)$ & -- & $7(3.1)$ \\
& & & \\
Acute meningitis & $3(2.9)$ & $2(1.6)$ & $5(2.2)$ \\
Chronic obstructive lung disease & & & \\
Diarrhoeal diseases & $1(1.0)$ & $3(2.4)$ & $4(1.7)$ \\
Renal diseases & $2(2.0)$ & $1(0.8)$ & $3(1.3)$ \\
Digestive diseases & $2(2.0)$ & $1(0.8)$ & $3(1.3)$ \\
Neoplasms & $1(4.3)$ & $2(1.6)$ & $3(1.3)$ \\
Diabetes & $2(2.0)$ & $0(0.0)$ & $2(0.9)$ \\
Other conditions & $1(1.0)$ & $2(1.6)$ & $3(1.3)$ \\
Undetermined & $5(4.9)$ & $7(5.6)$ & $12(5.3)$ \\
Overall total & $7(7.0)$ & $14(11.0)$ & $21(9.2)$ \\
\hline
\end{tabular}


Malaria accounted for $73.8 \%$ and $41.2 \%$ of deaths among the $<5$ years and 5-14 years age groups, respectively. HIV / AIDS was the second leading cause of mortality; accounting for $33.8 \%$ of all death in individuals of five years and above (Table 1). Among the sexually active age groups (15-60 years), HIV / AIDS accounted $43.4 \%$ of all deaths.
Of the 169 malaria attributable deaths recorded, $18.9 \%$ (32) and $137(81.1 \%)$ were classified as cerebral and clinical malaria, respectively. Majority ( $80.5 \%$ ) of the 169 reported deaths attributed to malaria occurred at health facilities. A higher proportion of malaria related deaths occurred at health facilities in the

Table 2: Distribution of causes of death by sex among children $<5$ years old in Muleba $(\mathrm{N}=191)$

\begin{tabular}{llll}
\hline Type of disease condition & $\begin{array}{l}\text { Sex } \\
\text { Female N (\%) }\end{array}$ & Male N (\%) & All N (\%) \\
\hline Malaria & $72(72.0 \%)$ & $69(75.8 \%)$ & $141(73.8 \%)$ \\
Protein energy malnutrition & $7(7.0 \%)$ & $6(6.6 \%)$ & $13(6.8 \%)$ \\
Diarrhoeal diseases & $3(3.0 \%)$ & $2(2.2 \%)$ & $5(2.6 \%)$ \\
Pneumonia & $3(3.0 \%)$ & $2(2.2 \%)$ & $5(2.6 \%)$ \\
& & & \\
Pyogenic meningitis & $1(1.0 \%)$ & $3(3.3 \%)$ I & $4(2.1 \%)$ \\
HIV/ AIDS & $3(3.0 \%)$ & 0 & $3(1.6 \%)$ \\
Chronic pulmonary infection & $1(1.5 \%)$ & 0 & $1(0.8 \%)$ \\
Nephrotic syndrome & $2(2.0 \%)$ & $1(1.1 \%)$ & $3(1.6 \%)$ \\
Sickle cell disease & $2(2.0 \%)$ & $1(1.1 \%)$ & $3(1.6 \%)$ \\
Neurological lesion/disease & $2(2.0 \%)$ & $1(1.1 \%)$ & $3(1.6 \%)$ \\
Injuries & $1(1.0 \%)$ & $2(2.2 \%)$ & $3(1.6 \%)$ \\
Other infection & $2(2.0 \%)$ & $3(3.3 \%)$ & $5(2.6 \%)$ \\
Undetermined & $1(1.0)$ & $1(1.1)$ & $2(1.1)$ \\
Overall total & 100 & 91 & 191 \\
\hline
\end{tabular}

Malaria was associated with the majority of deaths among the $<5$ years olds (Table 2). This was followed by protein energy malnutrition (marasmickwashiorkor=10and kwashiorkor=3), diarrhoeal diseases and pneumonia. Other conditions included measles (1), septicaemia (1), post-operative sepsis (1), and cardiovascular condition (2) (Table 2). epidemic areas $(85.9 \%)$ than in non-epidemic areas $(75.0 \%, P=0.0738)$. Significantly, a larger proportion of malaria related deaths occurred outside health facilities in non-epidemic (12.4\%) than epidemic areas $(7.1 \% ; P=0.0336)$. There was no significant difference in malaria related death by age group and clinical type of malaria between epidemic and non-epidemic areas (Tables 3).

Table 3: Malaria related death by age group, clinical type and place of death among $(\mathrm{N}=169)$ in Muleba District

\begin{tabular}{|c|c|c|c|c|c|}
\hline \multirow[t]{2}{*}{ Variable } & \multirow[t]{2}{*}{ Category } & \multirow[t]{2}{*}{ Total } & \multicolumn{3}{|c|}{ Malaria endemicity } \\
\hline & & & $\begin{array}{c}\text { Epidemic } \\
\text { N }(\%)\end{array}$ & $\begin{array}{l}\text { Non-epidemic } \\
\mathbf{N}(\%)\end{array}$ & $\begin{array}{l}P \text { - } \\
\text { value }\end{array}$ \\
\hline \multirow[t]{3}{*}{ Age group } & $1-59$ months & $141(83.4 \%)$ & $69(81.2 \%)$ & $72(85.7 \%)$ & 0.4314 \\
\hline & $5-14$ yrs & $14(8.3 \%)$ & $7(8.2 \%)$ & $7(8.3 \%)$ & 0.9812 \\
\hline & $15-70$ yrs & $14(8.3 \%)$ & $9(10.6 \%)$ & $5(6.0 \%)$ & 0.2788 \\
\hline \multirow[t]{2}{*}{ Clinical type } & Cerebral malaria & $32(18.9)$ & $14(16.5 \%)$ & $18(21.4 \%)$ & 0.4163 \\
\hline & Clinical malaria & 137(81.1) & $71(83.5 \%)$ & $66(78.6 \%)$ & 0.4163 \\
\hline \multirow[t]{2}{*}{ Place of death } & Health facility & $136(80.5 \%)$ & $73(85.9 \%)$ & $63(75.0 \%)$ & 0.0738 \\
\hline & Outside health facility & $33(19.5 \%)$ & $12(7.1 \%)$ & $21(12.4 \%)$ & 0.0336 \\
\hline
\end{tabular}


Overall malaria proportional mortality over 1997-2007 time interval was 40.3\%. Villages in the non-epidemic area had a slightly higher $(45.2 \%)$ malaria proportional mortality than villages in epidemic area $(36.5 \%$; $P=0.0713)$. However, villages in the lowlands areas had higher $(52.7 \%)$ significant malaria proportional mortality than villages in highlands (33.5 \%; $P=0.0001)$. About $58 \%$ of malaria occurred during two episodes of malaria outbreak (1997/ 1998 and 2005/2006) with overall malaria proportional mortality of $51.9 \%$ during that period. Peak of malaria proportional mortality was highest during malaria epidemic, 1997/1998 and 2005/2006 (Figure1). Malaria proportional mortality in villages in the epidemic was much lower than in non-epidemic areas during the non-epidemic years.

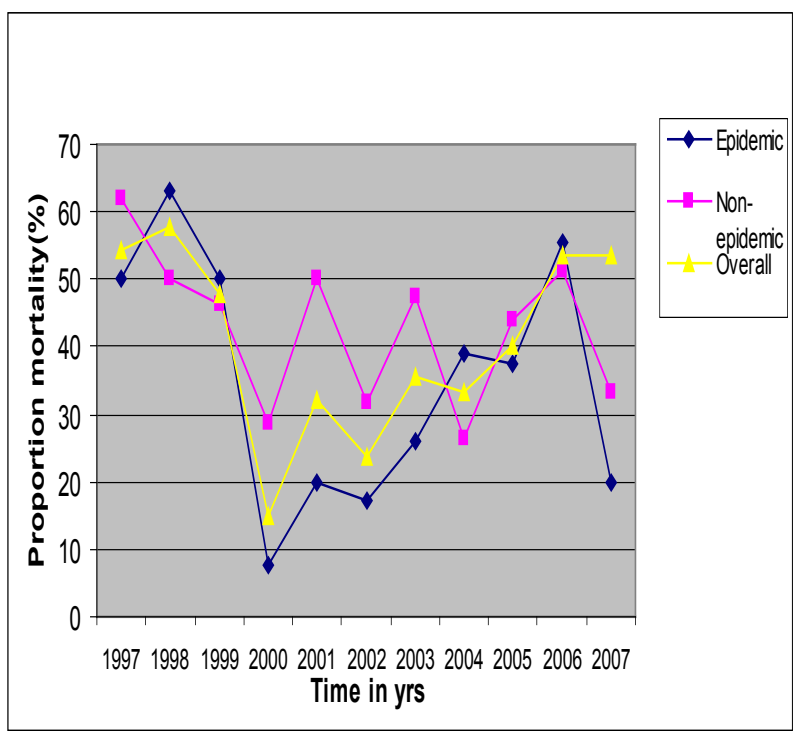

Figure1. Trend of malaria proportional mortality 1997- 2007

Children of $<5$ years accounted for most of death $(83.4 \%)$ attributed to malaria. Most of the malaria-related deaths in this group were among 1-12 months (64.5\%) followed by 1324 months $(20.6 \%)$, and $25-59$ months $(14.9 \%)$. Cerebral malaria accounted for 18.9\% (32/169) of death related to malaria in all age groups; $12.1 \%(17 / 141)$ were in underfive, $42.9 \%$ $(6 / 14)$ in 5-14 years old and $64.3(9 / 14)$ in 1570 years old. Similarly there was no difference in proportion of cerebral malaria related death as clinical type between epidemic and nonepidemic areas $(16.5 \%$ vs. $21.4 \%, P=0.4163)$ (Table 3). The highest proportion of death attributed to malaria were in Kibanga village (58.3\%), followed by Bushemba (49.1\%), Ikondo (46.4\%), Ijumbi (32.5\%) and Nshambya (31.8\%). Most cerebral malaria associated deaths were reported in Bushemba (12.7\%) (Figure2).

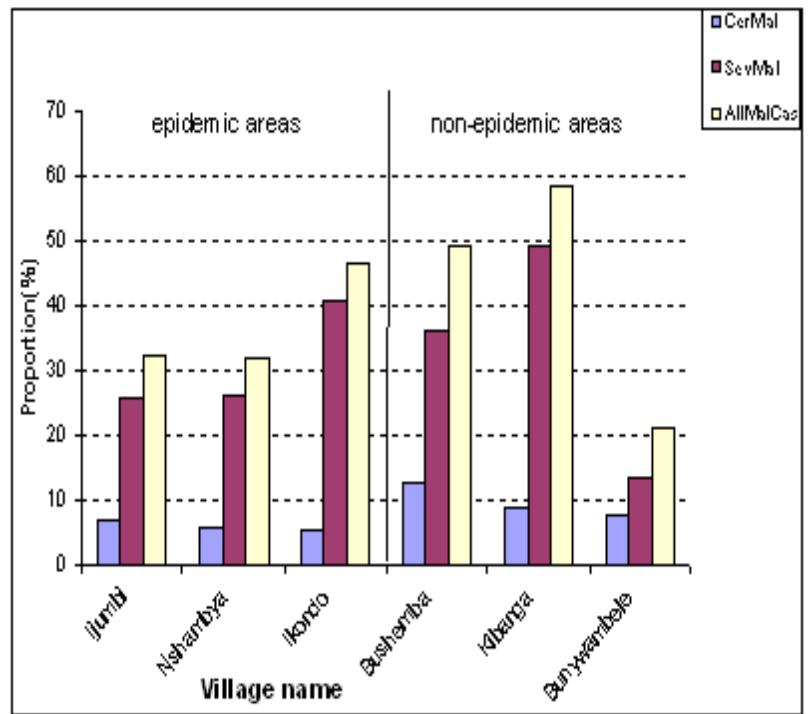

Figure1: Proportional cause of death attributed to malaria by village name

Key: CerMal = Cerebral malaria; SevMal =Severe malaria; AllMalcas = All malaria

More than half of malaria related deaths $(61.0 \%)$ in $<5$ years children were associated with severe anaemia followed by diarrhoeal disease $(24.1 \%)$, cerebral malaria $(12.5 \%)$ and respiratory infections $(8.5 \%)$ as common conditions. Some $19.9 \%$ of the caretakers reported their child to have an episode of febrile convulsion before death (Table 4). The deceased caretakers first sought treatment from health facilities for first time within $24 \mathrm{hr}$ of the onset of illness for $38(26.5 \%)$ deaths, 1-3 days for 70 (50\%) deaths and 4-7 days for $29(18.9 \%)$ deaths. The respective proportion of illness duration (between onset of illness and death) were $5.7 \% ; 29.8 \%$ and $27.7 \%$. However, a significantly higher proportion of caretakers of deceased under fives in the epidemic area sought treatment within $24 \mathrm{hr}$ than in non-epidemic area (39.3\% vs. $18.5 \% ; P=0.0385)$. 
Table 4: Malaria associated conditions, illness duration, treatment seeking and perceived cause of death among under fives $(\mathbf{N}=\mathbf{1 4 1})$

\begin{tabular}{|c|c|c|c|c|c|}
\hline \multirow[t]{2}{*}{ Variable } & \multirow[t]{2}{*}{ Category } & \multicolumn{3}{|c|}{ Number $(\%)$ of deaths } & \multirow[t]{2}{*}{ P-value } \\
\hline & & Total & Epidemic & Non-epidemic & \\
\hline \multirow{4}{*}{$\begin{array}{l}\text { Malaria } \\
\text { associated } \\
\text { condition }\end{array}$} & Anaemia & $86(61.0)$ & $40(58.0)$ & $46(63.9)$ & 0.4727 \\
\hline & Diarrhoea & $34(24.1)$ & $14(20.3)$ & $20(27.8)$ & 0.2981 \\
\hline & Convulsions & $28(19.9)$ & $14(20.3)$ & $14(19.4)$ & 0.8934 \\
\hline & LRI & $12(8.5)$ & $6(8.7)$ & $6(8.3)$ & 0.9321 \\
\hline \multirow{4}{*}{$\begin{array}{l}\text { Illness duration } \\
\text { before death }\end{array}$} & $\leq 1$ day & $8(5.7)$ & $5(7.3)$ & $3(4.2)$ & 0.4280 \\
\hline & 1 - 3 days & $42(29.8)$ & $20(29.0)$ & $22(30.6)$ & 0.8355 \\
\hline & $4-7$ days & $39(27.7)$ & $21(30.4)$ & $18(25.0)$ & 0.4736 \\
\hline & $>7$ days & $52(36.9)$ & $23(33.3)$ & $29(40.3)$ & 0.3891 \\
\hline \multirow{4}{*}{$\begin{array}{l}{ }^{*} \text { Time of seeking } \\
\text { care }\end{array}$} & $<$ I day & $35(26.5)$ & $23(34.3)$ & $12(18.5)$ & 0.0388 \\
\hline & 1- 3 days & $66(50.0)$ & $31(46.3)$ & $35(53.9)$ & 0.3826 \\
\hline & $4-7$ & $25(18.9)$ & $12(17.9)$ & $13(20.0)$ & 0.7582 \\
\hline & > 7days & $6(4.6)$ & $1(1.5)$ & $5(7.7)$ & 0.0876 \\
\hline \multirow{3}{*}{$\begin{array}{l}\text { Perceived cause } \\
\text { of death }\end{array}$} & Malaria illness & $31(93.6)$ & $63(92.7)$ & $68(94.4)$ & 0.6818 \\
\hline & Other diseases & $5(3.6)$ & $3(4.5)$ & $2(2.9)$ & 0.6151 \\
\hline & Unknown & $4(2.8)$ & $2(2.9)$ & $2(2.9)$ & 1.000 \\
\hline
\end{tabular}

Key: ${ }^{*} \mathrm{~N}=131 ; \mathrm{LRI}=$ lower respiratory infection

\section{Discussion}

Like elsewhere in Tanzania communicable diseases accounted for about two third of the causes of mortality in Muleba district $(\mathrm{MoH}$, 2006; Kamugisha et al., 2007). One major finding in the current study is the confirmation of malaria as the major cause of death in Muleba district. Malaria proportional mortality in the study district was even much higher than have been reported in high transmission areas in Tanzania (Premji et al., 1997; Salum et al. 1994). The high malaria-associated mortality is substantiated by healthcare facility-based data that indicate that $64.2 \%$ of deaths in $<5$ years is due to malaria (Kagera Region Report, 2005, unpubl). Recent studies have indicated that malaria prevalence in Muleba ranges from 49\% and 53.5\% (Mboera et al., 2006) indicating a change in endemicity in the area. More recent surveys have indicated that the overall prevalence of malaria in young children in Tanzania is $18 \%$, with Kagera Region having the highest rate (42\%) (THMIS, 2008). The occurrence of such high proportion death within 2 years of age among children is consistent with the fact that most children experience their first malaria infections during the first year or two of life, when they have not yet acquired adequate clinical immunity.

In our study, HIV / AIDS accounted for $43.3 \%$ of deaths in sexually active age group.
Similar findings have been reported in Uganda (Nunn et al., 2000). High prevalence of HIV/ AIDS in Kagera Region (including Muleba district) is likely to have influenced high mortalities observed in this study. The 6.8\% deaths attributed to malnutrition observed in our study is also likely to be associated with HIV / AIDS. Such high rate of HIV / AIDS and related opportunistic infections/conditions might have worsened and affected the pattern of malaria related mortality observed (Korenromp et al., 2005). In Kwa Zulu Natal, South Africa, an area of unstable malaria transmission, it has been observed that $8.8 \%$ and $2.7 \%$ fold increase in mortality among adults (Grimwade et al., 2004) and child (Grimwade et al., 2003) had severe malaria, respectively, associated with HIV-1 infection. The lack of difference in malaria related mortality pattern between the epidemic and non-epidemic villages is likely to be due to misclassification by criteria used based on the history of malaria epidemic. Village bordering the malaria epidemic prone area are likely to have equally being affected by the 2006 malaria epidemic.

Our findings indicate that anaemia, diarrhoea and cerebral malaria are common conditions associated with malaria among children in epidemic prone areas. Anaemia and cerebral malaria are the two major forms of severe disease leading to death. The risk 
of developing severe malaria is much higher in low and moderate transmission than high transmission area (Snow et al., 1997). Malarial anaemia may either develop rapidly following an acute malaria attack or may develop insidiously over a period of time (Abdalla et al., 1980). In epidemic prone area during malaria epidemic, an acute infectious anaemia is a phenomenon likely to be encountered. This is supported by the short illness duration revealed in our study. About one third of the deaths occurred within three days of the onset of illness. The substantial proportion of deaths attributed to cerebral malaria revealed in this study is another explanation for that short illness duration observed. In areas of lower transmission cerebral malaria predominates as a common complication and occurs at relatively older children whereas in high transmission severe anaemia usually occur in young children (Marsh \& Snow, 1999). This is consistent with acquisition of functional immunity. The association of diarrhoeal diseases with malaria illness among children has been reported elsewhere (Reither et al., 2007).

Late treatment seeking and deaths at home are common in Muleba like elsewhere in Tanzania. About three quarters of under-five caretakers' sought treatment at health facilities after 24 hours, suggesting that such high rate of malaria related mortality was likely to be attributed to the delay in seeking treatment. Most likely possible reason for such delays in seeking treatment is poor knowledge of malaria disease among under-five care takers as shown in a recent study in Muheza Tanzania (Ringsted et al., 2006), in Lake Victoria areas (Kaatano et al., 2006) and Mvomero (Mboera et al., 2009). Anaemia was poorly recognized and febrile convulsions were not associated with malaria among under-fives' caretakers. Seeking treatment outside the formal channel either from traditional healers (Kaatano et al., 2006) or self-medication with local herbs or modern medicine from drug sellers might result into delay in appropriate management of malaria. Other possible reasons are poverty and long distance to the health facilities. Therefore our findings suggest a need of promoting health seeking behaviour among communities in order to reduce mortality associated with malaria and other diseases among the children.

Our study had several limitations which include the cross-sectional study design rather than cohort and likelihood of having recall bias due to long duration of memory recall. The effect of memory recall might not be very significant due to the fact that sensitive life events like deaths are unlikely to be forgotten. Despite that limitation, our study has clearly shown an impact of malaria on mortality in Muleba district, with substantial proportion being attributed to malaria epidemics.

\section{Acknowledgements}

We are grateful to John Changalucha, Director, Mwanza Medical Research Centre for his logistic support. We thank the Muleba District Medical Officer and all village leaders and members of communities of the selected villages for their field assistance and cooperation. We are grateful to families of the bereaved for their willingness to provide information during the verbal autopsy interviews. Special thanks are to Ms Halaika Rwehumbiza and Mr Albert Bongo for their assistance in conducting verbal autopsy interview. This study received financial support from National Institute for Medical Research.

Received 15 August 2009

Revised 28 August 2009

Accepted 13 September 2009

\section{References}

Abdalla, S., Weatherall, D.J., Wickramasinghe, S.N. \& Hughes, M. (1980) The anaemia of P. falciparum malaria. British Journal of Haematology 46, 171-183.

Garay, J. (1998) Epidemiological survey and situation analysis: Malaria epidemic in Nshamba Division, Muleba District, Tanzania. MSF Spain 47 pp.

Grimwade, K., French, N., Mbatha, D.D., Zungu, D.D., Dedicoat, M. \& Gilks, C.F. (2003) Childhood malaria in a region of unstable transmission and high human immunodeficiency virus prevalence. Pediatrics Infectious Disease Journal 22, 1057-1063.

Grimwade, K., French, N., Mbatha, D.D., Zungu, D.D., Dedicoat, M. \& Gilks, C.F. (2004) HIV infection as a cofactor for severe falciparum malaria in adults living in a region of unstable malaria transmission in South Africa. AIDS 18, 547-554.

Lopez,A.D (1990) Causes of death: an assessment of global patterns of mortality around 1985. World Health Statistics Quarterly 43, 91-104. 
Kaatano, G.M., Muro, A.I.S. \& Medard, M. (2006) Caretakers' perceptions, attitudes and practices regarding childhood febrile illness and diarrhoeal diseases in riparian communities of Lake Victoria, in Tanzania. Tanzania Health Research Bulletin 8, 155-161.

Kamugisha, M.L., Gesase, S., Mlwilo, T.D, Mmbando, B.P, Segeja, M.D, Minja, D.T, Massaga, J.J., Msangeni, H.A., Ishengoma, D.R. \& Lemnge, M.M. (2007) Malaria specific mortality in lowlands and highlands of Muheza district, north-eastern, Tanzania. Tanzania Health Research Bulletin 9, 32-37.

Korenromp, E.P., Williams, B.G., de Vlas, S.J., Gouws, E., Gilks, C.F., Ghys, P.D. \& Nahlen, B.L (2005) Malaria attributable to the HIV-1 epidemic, sub-Saharan Africa. Emerging Infectious Disease 11, 1410-1419.

Maegga, B.T.A., Cox, J. \& Malley, K.D. (2005) Malaria in the southern highlands of Tanzania: a review of hospital records. Tanzania Health Research Bulletin 7, 125132.

Marsh, K. \& Snow, R.W. (1999) Malaria transmissionand morbidity.Parassitologia 41, 241-246.

Mboera, L.E.G. (2004) Environmental and socio-economic determinants of malaria epidemics in highlands of Tanzania. Tanzania Health Research Bulletin 6, 11-17.

Mboera, L.E.G., Fanello, C.I., Malima, R.C., Talbert, A., Fogliati, P., Bobbio, F. \& Molteni, F. (2006) Comparison of the Paracheck-Pf test to microscopy for confirmation of Plasmodium falciparum malaria in Tanzania. Annals of Tropical Medicine E Parasitology 100, 115-122.

Mboera, L.E.G. \& Kitua, A.Y. (2001) Malaria epidemics in Tanzania: an overview. African Journal of Health Sciences 8, 17-23.

Mboera, L.E.G., Makundi, E.A. \& Kitua, A.Y. (2007) Uncertainty in malaria control in Tanzania: crossroads and challenges for future interventions. American Journal of Tropical Medicine and Hygiene 77 (Suppl 6), 112-118.

Mboera, L.E.G., Shayo, E.H., Senkoro, K.P., Rumisha, S.F., Mlozi, M.R.S., Mayala, B.K. (2009) Knowledge, perceptions and practices of farming communities on linkages between malaria and agriculture in Mvomero District, Tanzania. Acta Tropica 112, 000-00 (in press)
Mghamba, J.M., Mboera, L.E.G., Krekamoo, W., Senkoro, K.P., Rumisha, S.F., Shayo, E.H. \& Mmbuji, P. (2004) Challenges of implementing Integrated Disease Surveillance and Response strategy using the current Health Management Information System in Tanzania. Tanzania Health Research Bulletin 6, 57-63.

$\mathrm{MoH}$ (2006) Annual Health Statistics Abstract 2006. Ministry of Health and Social Welfare, Dar-es-Salaam, United Republic of Tanzania

Nunn, A.J., Mulder, D.W., Kamali, A., Ruberantwari, A., Kengeya-Kayondo, J.F. \& Whitworth, J. (1997) Mortality associated with HIV-1 infection over five years in a rural Ugandan population: cohort study. BMJ 315 (7111), 767-771

Premji, Z., Ndayanga, P., Shiff, C., Minjas, J., Lubega, P. \& MacLeod, J. (1997) Community based studies on childhood mortality in a malaria holoendemic area on the Tanzanian coast. Acta Tropica 63, 101-109.

Reither, K., Ignatius, R., Weitzel, T., SeiduKorkor, A., Anyidoho, L., Saad, E., DjieMaletz, A., Ziniel, P., Amoo-Sakyi, F., Danikuu, F., Danour, S., Otchwemah, N.R., Schreier, E., Bienzle, U., Stark, K. \& Mockenhaupt, F.P. (2007 )Acute childhood diarrhoea in northern Ghana: epidemiological, clinical and microbiological characteristics BMC Infectious Disease 7, 104.

Ringsted, F.M., Bygbjerg, I.C. \& Samuelsen, H. (2006) Early home-based recognition of anaemia via general danger signs, in young children, in a malaria endemic community in north-east Tanzania. Malaria Journal 5, 111.

Rumisha, S.F., Mboera, L.E.G., Senkoro, S.F., Gueye, D. \& Mmbuji, P.L. (2007) Monitoring and evaluation of Integrated Disease Surveillance and Response in selected Districts in Tanzania. Tanzania Health Research Bulletin 9, 1-11.

Salum, F.M., Wilkes, T.J., Kivumbi, K. \& Curtis, C.F. (1994) Mortality of underfives in a rural area of holoendemic malaria transmission. Acta Tropica 58, 29-34.

Snow, R.W., Armstrong, J.R.M., Forster, D., Winstanley, M.T., Marsh, V.M., Newton, C.R.J.C., Waruiru, C., Mwangi, I., Winstanley, P.A. \& Marsh, K. (1992) Childhood deaths in Africa: uses and 
limitations of verbal autopsies. Lancet 340, 351-335.

Snow, R.W., Omumbo, J.A., Lowe, B., Molyneux, C.S., Obiero, J.O., Palmer, A., Weber, M.W., Pinder, M., Nahlen, B., Obonyo, C., Newbold, C., Gupta, S. \& Marsh, K. (1997) Relation between severe malaria morbidity in children and level of Plasmodium falciparum transmission in Africa. Lancet 349(9066), 1650-1654.

Snow, R.W., Craig, M., Deichmann, U. \& Marsh, K.(1999) Estimating mortality, morbidity and disability due to malaria among Africa's non-pregnant population. Bulletin of the World Health Organization 77, 624-640.
Soleman, N., Chandramohan, D. \& Shibuya, K. (2006) Verbal autopsy: current practices and challenges. Bulletin of the World Health Organization 84, 239-245.

THMIS (2008) Tanzania HIV and Malaria Indicator Survey 2007-08. Preliminary Report. Tanzania Commission for AIDS.

URT (2002) Population and Housing Census General Report. Central Census Office National Bureau of Statistics, President's Office, Planning and Privatization Government Printers United Republic of Tanzania 2003:203 pp.

WHO (2007) Verbal Autopsy Standards: Ascertaining and Attributing Cause of Death. World Health Organization, Geneva. 